\title{
ANÁLISE DE RISCO DAS OPERAÇÕES DE MICROCRÉDITO
}

\section{RISK ANALYSIS OF MICROCREDIT'S OPERATIONS}

Eliana Marcia Martins Fittipaldi Torga

Doutoranda em Administração na Universidade Federal de Minas Gerais

Belo Horizonte, MG, Brasil

E-mail: eliana_torga@yahoo.com.br

Francisco Vidal Barbosa

Docente do Departamento de Administração da FACE - UFMG

Belo Horizonte, MG, Brasil

E-mail: fvberlim@gmail.com

Bruno Pérez Ferreira

Docente do Departamento de Administração da FACE - UFMG

Belo Horizonte, MG, Brasil

E-mail: brunoperez.bh@gmail.com

\section{RESUMO}

No Brasil, o microcrédito tem sido aplicado para o combate à pobreza e estímulo ao crescimento e desenvolvimento econômico. É uma operação de crédito que constitui um dos temas relevantes estudados pela área da administração financeira. Esta pesquisa buscou investigar mediante a utilização das técnicas de duração e convexidade, qual é o risco das operações de microcrédito realizadas por bancos governamentais brasileiros e abordou o tema com relação á gestão de risco de crédito. Este estudo verificou que as oscilações nas taxas constituem um risco, que pode causar problemas nos resultados financeiros das Instituições de Microfinanças se os retornos obtidos no cumprimento das obrigações contratadas passarem a ser insuficientes. As parcerias institucionais com agências de desenvolvimento podem se constituir um importante fator para garantir a concessão de crédito. Sugeremse novos estudos para a análise das regulamentações do setor, os métodos de concessão e a avaliação de risco das operações.

Palavras-chave: Crédito. Microcrédito. Análise de Risco. Duração. Convexidade.

Data de submissão: 26 de outubro de 2014.

\section{ABSTRACT}

In Brazil, microcredit has been applied to fighting poverty and stimulating economic growth and development. It is a loan that is one of the important issues studied by the area of financial management. This research aimed to investigate by using the techniques of duration and convexity, which is the risk of microcredit operations performed by banks Brazilian government raised the issue with respect to the management of credit risk. This study found that the rate fluctuations are a risk, which can cause problems in the financial results of Microfinance Institutions if the returns earned on the obligations contracted spend insufficient. Institutional partnerships with development agencies can be an important factor to ensure the provision of credit. Further studies are suggested for the analysis of industry regulations, methods of risk assessment and granting of operations.

Keywords: Credit. Microcredit. Risk Analysis. Duration. Convexity.

Data de aprovação: 10 de fevereiro de 2017. 


\section{INTRODUÇÃO}

O tema da inclusão, no mercado financeiro, de pessoas sem condição de acesso às instituições financeiras ganha espaço cada vez maior nos fóruns de discussões. A matéria não constitui preocupação apenas em termos de apelo social. Busca-se, além da inclusão das minorias e da equidade, o incremento e o aquecimento da economia, mediante o incentivo a maior movimentação financeira.

Dentre os oito objetivos de desenvolvimento do milênio, estabelecido em 2000 pela ONU, a partir da análise dos maiores problemas mundiais, a redução da pobreza é a prioridade no século 21. Apesar do enorme progresso nos últimos 50 anos, cerca de 1,7 bilhões de pessoas que vivem em países cobertos pelo Índice de Pobreza Multidimensional - IPM (um terço de sua população) sofrem de pobreza multidimensional. Esse quantitativo ultrapassa a estimativa de 1,44 bilhões de pessoas que vivem com USD 1,25, ou menos, por dia, conforme o Relatório do Desenvolvimento Humano de 2010 do Programa das Nações Unidas para o Desenvolvimento do Brasil. (ORGANIZAÇÃO DAS NAÇÕES UNIDAS. PNUD/BRASIL, 2012 a).

O microcrédito é entendido como a principal atividade do setor de microfinanças, pela importância que representa para as políticas de superação da pobreza pela geração de trabalho e renda, matéria objeto de preocupação das diversas esferas de governo. Em face desse entendimento, o Governo Federal lançou em 2011 o Plano Brasil sem Miséria, que contempla em seu escopo a ampliação da política de microcrédito e incentivo à economia popular e solidária, entre outras ações de inclusão social. Com essa iniciativa, esperase beneficiar dois milhões de pessoas. Essa estratégia do Governo Federal será executada, juntamente com Estados e Municípios, em cada região onde estão sendo mapeadas a pobreza e as oportunidades (BRASIL, 2011 a).

A indústria de microcrédito tem-se apresentado como uma alternativa para a oferta de crédito no País, permitindo aos sem capital acesso a capital produtivo, possibilitando-lhes sua inclusão financeira e social, além de provocar mudanças econômicas, pessoais, sociais e políticas.

Considerando o exposto e tomando como base o crescimento do mercado de microfinanças na atualidade, julgou-se pertinente e oportuna a realização de estudo a respeito do risco da operação, uma vez que poderá trazer relevante contribuição para as discussões acerca da gestão de risco das operações de microcrédito nos Bancos governamentais brasileiros, além de auxiliar os gestores públicos e as Instituições de Microfinanças quanto à tomada de decisão a respeito de medidas preventivas de risco. 


\section{REFERENCIAL TEÓRICO}

\section{Microcrédito}

O microcrédito foi mundialmente difundido em Bangladesh, coordenada pelo Professor Muhamad Yunus, que desenvolveu o método como atualmente ele é conhecido. O programa de microcrédito desenvolvido pelo Grameen Bank, em Bangladesh, iniciativa do Professor Muhammad Yunus, levou-o a ser distinguido com o Prêmio Nobel da Paz, em 2006.

Yunus (2001) relata que a prática do microcrédito, através da criação de um banco para emprestar dinheiro para pobres, foi instituída por ele mesmo, após o ano de 1974, ano em que Bangladesh enfrentou um período de fome, que dizimou muitas pessoas.

Segundo Soares e Sobrinho (2008), a atividade de microcrédito é definida como aquela que, no contexto das microfinanças, dedica-se a prestar tais serviços exclusivamente a pessoas físicas e jurídicas empreendedoras de pequeno porte. Diferencia-se dos demais tipos de atividade microfinanceira também pela metodologia utilizada, diversa daquela adotada para as operações de crédito tradicionais. É entendida como a principal atividade do setor de microfinanças, pela importância para as políticas públicas de superação da pobreza e também pela geração de trabalho e renda.

Soares (2008) define microcrédito como a atividade que, no contexto das microfinanças, dedica-se a prestar serviços a pessoas físicas e jurídicas empreendedoras de pequeno porte, diferenciando-se dos demais tipos de atividade microfinanceira essencialmente pela metodologia utilizada, bastante diferente daquela adotada para as operações de crédito tradicionais. É comumente entendida como a principal atividade do setor de microfinanças, pela importância que representa para as políticas de superação da pobreza e geração de trabalho e renda.

Ao focalizar a base da pirâmide social e empresarial, o crédito pode ser utilizado como ferramenta de inclusão social, seja através de sua orientação para o consumo ou, de forma considerada mais nobre, ao prover recursos para atividades produtivas (Barone et al., 2007). O microcrédito e as microfinanças situamse no âmbito do acesso a crédito e outros serviços financeiros por parte de clientes de baixa renda.

A Lei no 11.110, de 25 de abril de 2005, instituiu o Programa Nacional de Microcrédito Produtivo Orientado (MPO), possibilitando a concessão de crédito, condicionada aos seguintes requisitos:

a) atendimento às necessidades financeiras de pessoas físicas e jurídicas empreendedoras de atividades produtivas de pequeno porte, com renda bruta anual de até $R \$ 120.000,00$ (cento e vinte mim reais), conforme dispõe o Decreto № 6.607 de 21 de outubro de 2008;

b) utilização de metodologia baseada no relacionamento direto com os empreendedores, no local onde é executada a atividade econômica.

c) atendimento ao tomador final dos recursos por pessoas treinadas para efetuar o levantamento socioeconômico e prestar orientação educativa sobre o planejamento do negócio, para definição das necessidades de crédito e de gestão voltadas para o desenvolvimento do empreendimento;

d) manutenção de contato com o tomador final dos recursos, durante o período do contrato, para acompanhamento e orientação. 
Quanto ao valor e às condições do crédito, a citada Lei prevê sua definição após a avaliação da atividade e da capacidade de endividamento do tomador final dos recursos.

Outra iniciativa do Governo Federal para facilitar o acesso ao crédito orientado, como forma de incentivo ao crescimento de pequenos empreendimentos e à geração de trabalho e renda é o Programa Crescer, lançado em 2011 pelo Governo Federal. Tem o objetivo de fornecer crédito a juros mais baixos a microempreendedores individuais e microempresas. Até o final de 2013 , a meta é atender 3,4 milhões de clientes. O Crescer tem juros de $8 \%$ ao ano, bem abaixo das taxas atualmente praticadas no microcrédito, que chegam até a $60 \%$ ao ano. Além dos juros mais baixos, a Taxa de Abertura de Crédito (TAC) também teve redução, passando de $3 \%$ sobre o valor financiado para $1 \%$ sobre o valor do crédito. (BRASIL, 2011).

\section{Crédito}

A operação de crédito denominada "microcrédito", tema de particular interesse da área da administração financeira, será nesta seção abordado quanto à gestão de risco de crédito dos bancos brasileiros, mediante a aplicação das técnicas de duração e convexidade. As operações de microcrédito possuem as características das operações financeiras de crédito que são objeto dos estudos de renda fixa e neste estudo será desenvolvida essa correlação, numa abordagem teórica.

\section{Conceito de Crédito}

Segundo Ferreira (1995), a palavra "crédito" é originária do latim creditu e significa, em sentido lato, a segurança de que alguma coisa é verdadeira, confiança/crença, boa fama/reputação. Para Silva (2006), em sentido econômico restrito, o crédito consiste na entrega de valor (mercadoria, serviço ou importância em dinheiro) para pagamento futuro, mediante promessa estabelecida. O crédito carrega um significado profundo, que emerge da confiança, por parte de quem o concede, no potencial daquele que o recebe de multiplicar esse valor, e, assim, possibilitar a solvabilidade do montante emprestado. Ventura (2000) enfatiza que conceder crédito a uma pessoa é, em essência, acreditar nela.

Segundo Silva (2006), o crédito desempenha papel econômico e social, uma vez que:

e) Possibilita às empresas aumentarem seu nível de atividade;

f) Estimula o consumo influenciando na demanda;

g) Ajuda as pessoas a obterem a moradia, bens e até alimentos;

h) Facilita a execução de projetos para os quais as empresas não disponham de recursos próprios suficientes.

Silva (2006) observa que os empréstimos ou financiamentos, assim como as operações de microcrédito, carregam características de risco inerentes à sua finalidade e à sua natureza. Os principais componentes de uma operação dessa natureza são: produto, montante prazo, forma de pagamento, garantias e preços. Ensina o autor que cada um desses componentes tem potencial de risco: a inadequação do valor ou do produto pode levar à inadimplência; o prazo precisa ser compatível com a capacidade de pagamento 
do cliente; a garantia associada a cada operação de empréstimo ou financiamento, quanto à sua liquidez e suficiência é de relevante importância. Segundo Silva (2006), a separação entre o risco do cliente e da operação possibilita uma análise e decisão mais apropriadas.

\section{Características das Operações de Crédito}

Silva (2006) considera ser funções do crédito captar recursos junto aos agentes econômicos com posição orçamentária superavitária e financiar as necessidades de investimentos e consumo dos agentes com situação orçamentária deficitária. É também função do crédito avaliar a capacidade de pagamento do tomador, visando a assegurar o retorno do investimento e a solidez do banco.

Segundo Assaf Neto (2007), os contratos de empréstimo são firmados com a promessa de pagamento, a seus investidores, de um determinado fluxo futuro de rendimentos e de juros periódicos, ou de um determinado montante fixo, no final do prazo de emissão. A avaliação desses títulos é processada por meio de fluxo de caixa prometido ao investidor, o que envolve a maturidade, descontando-se uma taxa que reflita o risco do investimento (GREENWOOD, HANSON, STEIN, 2010).

Os juros pagos pelos bônus são representados por cupons, e as taxas podem ser fixas (percentual do principal) ou variáveis, sendo o valor calculado de acordo com os referenciais estabelecidos. O capital aplicado pode ser pago em valores periódicos, ou integralmente, no vencimento.

Assaf Neto (2007) observa que os principais riscos a que um investidor se expõe ao adquirir esses títulos são: (i) oscilações nas taxas de juros de mercado; (ii) inadimplência do emitente; (iii) liquidez do mercado; e (iv) oportunidades de reinvestimento dos fluxos de caixa recebidos pelo investidor.

Segundo Fabozzi (2000) e Assaf Neto (2007), a volatilidade de um bônus é entendida como as mudanças ocorridas nos preços do título, em razão de modificações verificadas nas taxas de juros do mercado. Para Fabozzi (2000), um dos principais riscos enfrentados no mercado de bônus é o da taxa de juros vir a subir, reduzindo o preço de um bônus, em virtude de sua à oscilação na taxa de juros. Estudos demonstram que alterações na carga tributária e outros fatores macroeconômicos são determinantes estatisticamente e economicamente na avaliação do risco (AIZENMAN ET AL, 2013).

A análise da sensibilidade de um bônus pode ser realizada por meio de duas técnicas que são usualmente empregadas em análises de investimento em renda fixa: duração e convexidade. Ambas podem ser aplicadas em situações semelhantes, como as operações de créditos do ponto de vista da instituição financeira, que investe seus recursos na emissão de contratos de financiamento, com uma taxa de retorno que compense a realização da operação (VARGAS, 2012).

A técnica de duração de um título expressa o tempo médio que o investidor deve esperar, para receber os pagamentos prometidos, a valor presente. Assaf Neto (2007) e Fabozzi (2000), reportando-se a uma técnica de cálculo conhecida como "Duração de Macaulay", nome de seu desenvolvedor, explicam que se trata de uma maneira diferente de proceder ao cálculo da duração, levando em conta os fluxos de caixa ponderados pelas respectivas maturidades, trazidas a valor presente pela taxa de atratividade. 
A expressão da Duração de Macaulay é assim formulada:

Duração de Macaulay $=\frac{\sum_{t=1}^{n} \frac{t C}{(1+y)^{t}}+\frac{n M}{(1+y)^{n}}}{P}$

Onde:

$\mathrm{D}=$ duração

$y=$ Taxa de juros da operação (YTM)

$C F_{j}=$ fluxo caixa previsto para $\mathrm{p}$ período $\mathrm{j}$

$P_{0}=$ preço de mercado do título

$\mathrm{j}$ = maturidade de cada fluxo de caixa (valor de negociação)

As modificações no preço de um título, diante das variações nas taxas de juros, podem ser determinadas por meio de uma modificação na Duração de Macaulay, obtida através da expressão:

Duração Modificada $(M D)=\frac{\text { Duração de Macaulay }}{1+Y T M}$

Assaf Neto (2011) observa que "a duração modificada revela a variação na cotação do título para cada $1 \%$ de variação nos juros de mercado". Fabozzi (2000), Hatchondo e Martinez (2009) destacam ainda que, quanto maior for a maturidade, maior será a volatilidade de preço e maior a duração modificada; quanto mais baixa for a taxa de cupom, maior será a volatilidade do preço, e maior a duração modificada. Quanto maior for a duração modificada, maior será a volatilidade de preço do bônus, logo a duração constitui em uma medida de avaliação do risco, o que corrobora com Bai e Zhang (2012).

Segundo Fabozzi (2000), a medida da duração pode ser complementada por uma medida adicional, para capturar a curvatura ou convexidade de um bônus. É possível traçar uma tangente para a relação preço/retorno, no retorno $y^{*}$. A tangente mostra a razão da variação de preço relativamente a uma variação nas taxas de juros naquele ponto (nível de retorno).

A linha tangencial e a medida de duração são suficientes para estimar o preço efetivo para pequenas variações de retorno. Contudo, quanto mais se afasta do retorno inicial $\mathrm{y}^{*}$, mais distante do preço efetivo estará o preço estimado, como demonstrado por Fabozzi (2000), segundo o qual, a medida da duração pode ser complementada com uma medida adicional, para capturar a curvatura (convexidade) de um bônus. Isto poderá ser feito através de um relacionamento matemático, como a equação de convexidade, a partir da série de Taylor, utilizada para aproximar a variação do preço e dividindo-se ambos os membros da equação acima por $P$, para obter a variação percentual de preço, chega-se a uma nova equação:

$\frac{d P}{P}=\frac{d P}{d y} \frac{1}{P} d y+\frac{1}{2} \frac{d^{2} P}{d y^{2}} \frac{1}{p}(d y)^{2}+\frac{\text { erro }}{P}$ 
Como se pode observar, a segunda derivada do preço $\left(\frac{\mathrm{d}^{2} \mathrm{P}}{\mathrm{dy}^{2}}\right)$ é que determina a convexidade do bônus:

Convexidade em moeda $=\frac{d^{2} P}{d y^{2}}$

Convexidade $=\frac{d^{2} P}{d y^{2}} \frac{1}{P}$

Var. preço estimada pela convexidade: $\mathrm{dP}=\frac{d^{2} P}{d y^{2}}(d y)^{2}$

Var. percentual de preço devido à convexidade: $\frac{d P}{P}=\frac{1}{2} \frac{d^{2} P}{d y^{2}} \frac{1}{P}(d y)^{2}$

\section{METODOLOGIA}

Trata-se de um estudo de multicasos com abordagem exploratória e descritiva. Nesta pesquisa desenvolveu-se análise qualitativa dos dados coletados por meio de observação participante e entrevistas aos agentes de crédito e análise quantitativa no tratamento dos dados financeiros, por meio de uma análise de Engenharia Financeira pelo estudo das operações financeiras, conforme técnicas dessa área do conhecimento.

O estudo foi realizado em bancos governamentais que trabalham com o microcrédito, quais sejam, Banco do Nordeste, Banco do Brasil e Caixa Econômica Federal, objetivando estabelecer um paralelo entre os bancos estudados, com vistas a uma melhor compreensão da influência das variáveis nos resultados. A amostra foi composta por gestores, agentes de crédito dos bancos governamentais (Banco do Brasil, Banco do Nordeste e Caixa Econômica Federal), que trabalham com o microcrédito na Região Metropolitana de Belo Horizonte.

As informações coletadas e utilizadas na análise quantitativa referem-se à caracterização das linhas de microcrédito nos bancos estudados, quais sejam, as condições de contratação do valor do crédito, taxas de juros e prazos. O estudo quantitativo utilizado nesta pesquisa envolveu a aplicação dos fatores montante, taxa de juros e prazo, e a mensuração da volatilidade, a partir das técnicas de duração e convexidade.

Foram seguidas na pesquisa as mesmas etapas descritas por Fabozzi (2000). Para cada linha de crédito, foi determinado um aumento do retorno do bônus por um número pequeno de pontos-base, de forma a encontrar o novo preço dos títulos em nível mais elevado, sendo este novo preço denotado por $\mathrm{P}+$. Simultaneamente, foi determinada a redução do retorno do bônus pelo mesmo número de pontos-base, para, então, calcular o novo preço, denotado por P.. Sendo $P_{0}$ o preço inicial, a duração será aproximada, por meio da formula:

Duração aproximada $=\frac{P_{-}-P+}{2\left(P_{0}\right)(\Delta \gamma)}$

O termo $\Delta \gamma$ corresponde à variação na taxa utilizada para calcular os novos preços, em forma decimal. Essa equação mede a variação percentual de preço, relativa ao preço inicial, por variação de retorno de um ponto-base. 
Neste trabalho, foi utilizada a aproximação por convexidade, técnica apresentada por Fabozzi (2000), por meio da seguinte fórmula:

Convexidade aproximada $=\frac{P_{+}+P_{-}-2 P_{0}}{P_{0}(\Delta \gamma)^{2}}$

\section{Análise e Interpretação dos Dados}

No estudo quantitativo, foram calculados os valores mensais da duração e da convexidade. Os resultados obtidos após serem organizados em uma tabela, separados por carteira dos Bancos pesquisados, foram analisados com base nas teorias financeiras expostas nesta pesquisa, que buscou encontrar uma relação entre a variação das taxas e o risco de crédito desse tipo de operação.

Para o tratamento dos dados qualitativos, foi realizada uma análise qualitativa das entrevistas através da técnica de análise temática ou categorial, que de acordo com Bardin (2002), baseia-se em operações de desmembramento do texto em unidades, ou seja, descobrir os diferentes núcleos de sentido que constituem a comunicação.

Os dados coletados durante a entrevista com os agentes de crédito foram subdividos por categorias temáticas que apresentaram relevância para esta pesquisa. A análise dos dados foi realizada em correlação com as teorias que embasam este estudo.

\section{INSTITUIÇÕES PESQUISADAS}

As informações que constam desta sessão foram obtidas em documentos públicos e nos sites das instituições pesquisadas.

\section{Banco do Nordeste do Brasil}

Segundo informações coletadas no Banco do Nordeste do Brasil, (2012 c), ele opera como órgão executor de políticas públicas, cabendo-Ihe a operacionalização de programas como o Crediamigo. Integra o Crescer - Programa Nacional de Microcrédito do Governo Federal.

O Quadro 1, a seguir, sintetiza os critérios e condições para obtenção de microcrédito no Banco do Nordeste. 
Quadro 1 - Operações de microcrédito do Banco do Nordeste: critérios e condições-2012

\begin{tabular}{|l|l|l|}
\hline Nome do produto & Crediamigo Crescer Individual & Crediamigo Crescer Solidário \\
\hline Público & $\begin{array}{l}\text { Empreendedores individuais ou } \\
\text { reunidos em grupos solidários }\end{array}$ & $\begin{array}{l}\text { Empreendedores individuais ou reunidos em grupos } \\
\text { solidários }\end{array}$ \\
\hline Empreendedor & Pessoa física & Pessoa jurídica \\
\hline Taxa & $\begin{array}{l}\text { Aquisição de máquinas, } \\
\text { equipamentos e reformas }\end{array}$ & $\begin{array}{l}\text { Aquisição de matéria prima/mercadorias e } \\
\text { equipamentos }\end{array}$ \\
\hline Limites & $0,64 \%$ ao mês & $0,64 \%$ ao mês \\
\hline Prazo & $\mathrm{R} \$ 300,00$ até R $\$ 6.000,00$ & $\begin{array}{l}\text { Empréstimos de } \mathrm{R} \$ 100,00 \text { a R } \$ 2.000,00 \text { para } \\
\text { bancos comunitários e grupos solidários; }\end{array}$ \\
\hline Carência & 36 meses & 4 até 12 meses \\
\hline Forma de liberação & não informado & não informado \\
\hline TAC & $1 \%$ & não informado \\
\hline IOF & 0 & $1 \%$ \\
\hline Garantia & Coobrigado & 0 \\
\hline Fon carência & $\begin{array}{l}\text { Grupo solidário ou bancos comunitários de 15 a } 30 \\
\text { pessoas. }\end{array}$ \\
\hline
\end{tabular}

Fonte: Elaborado pelos autores.

\section{Caixa Econômica Federal}

O Microcrédito Crescer, Programa da Caixa Econômica Federal, está voltado para a concessão de empréstimos para a aquisição de equipamentos e materiais de construção. Os valores dos empréstimos estão entre $R \$ 300,00$ e $R \$ 15.000,00$ com taxa de juros de $0,64 \%$ ao mês, com prazo de até 12 meses. O Quadro 2, a seguir, apresenta os critérios e condições para obtenção de microcrédito na Caixa Econômica Federal.

Quadro 2 - Operações de microcrédito da Caixa Econômica Federal: critérios e condições - 2012

\begin{tabular}{|l|l|l|}
\hline Nome do Produto & $\begin{array}{l}\text { Programa Microcrédito Produtivo Orientado } \\
\text { CRESCER CAIXA }\end{array}$ & $\begin{array}{l}\text { Programa Microcrédito Produtivo Orientado } \\
\text { CRESCER CAIXA }\end{array}$ \\
\hline Empreendedor & Pessoa física & Pessoa jurídica \\
\hline Finalidade & $\begin{array}{l}\text { maior de 18 anos ou emancipado e possuir } \\
\text { conta na CAIXA }\end{array}$ & Não informado \\
\hline Taxa & $\begin{array}{l}\text { comprar equipamentos, matéria-prima ou } \\
\text { melhorar o ambiente do seu negócio. }\end{array}$ & Não informado \\
\hline Limites & $0,64 \%$ a.m & Não informado \\
\hline Prazo & R $\$ 300,00$ a R $\$ 15.000,00$ & Não informado \\
\hline Carência & 12 meses & Não informado \\
\hline $\begin{array}{l}\text { Forma de } \\
\text { liberação }\end{array}$ & Sem & Sem \\
\hline TAC & Fácil corrente, poupança ou conta CAIXA & conta corrente, poup, ou conta CAIXA Fácil \\
\hline IOF & $1 \%$ & Não informado \\
\hline Garantias & Não informado & Não informado \\
\hline
\end{tabular}

Fonte: Elaborado pelos autores. 


\section{Banco do Brasil}

O BB Microcrédito Empreendedor é o crédito que o Banco do Brasil - BB oferece para atender às necessidades financeiras de pessoas físicas e jurídicas empreendedoras de atividades produtivas de pequeno porte. $\mathrm{O}$ atendimento ao cliente por meio de relacionamento direto com funcionários do Banco, preparados para orientar e acompanhar o desenvolvimento sustentável dos seus negócios.

O Quadro 3, a seguir, sintetiza os critérios e condições para obtenção de microcrédito no Banco do Brasil.

Quadro 3 - Operações de microcrédito do Banco do Brasil: critérios e condições - 2012

\begin{tabular}{|c|c|c|}
\hline Nome do Produto & BB Microcrédito Empreendedor PF & BB Microcrédito Empreendedor PJ \\
\hline Empreendedor & Pessoa física & Pessoa jurídica \\
\hline Público & $\begin{array}{l}\text { Pessoas físicas empreendedoras de } \\
\text { atividades produtivas de pequeno porte }\end{array}$ & $\begin{array}{l}\text { Empreendedores Individuais (EI), Micro e } \\
\text { Pequenas Empresas (MPE) com faturamento } \\
\text { de até } \mathrm{R} \$ 120.000,00 / a n o \text {. }\end{array}$ \\
\hline Finalidade & Giro e investimento & $\begin{array}{l}\text { Giro na forma de teto pré-aprovado } \\
\text { e Investimento na forma de crédito fixo. }\end{array}$ \\
\hline Taxa & $0,64 \%$ a.m ( $8 \%$ ao ano) & $0,64 \%$ a.m ( $8 \%$ ao ano) \\
\hline Limites & $\mathrm{R} \$ 150,00$ a $\mathrm{R} \$ 15.000,00$ & $\mathrm{R} \$ 150,00$ a $\mathrm{R} \$ 15.000,00$ \\
\hline Prazo & $\begin{array}{l}\text { Giro: de } 4 \text { a } 6 \text { meses Investimento: de } 4 \text { a } 12 \\
\text { meses }\end{array}$ & $\begin{array}{l}\text { Giro: até } 12 \text { meses } \\
\text { Investimento: até } 18 \text { meses }\end{array}$ \\
\hline Carência & 30 a 59 dias & 30 a 59 dias \\
\hline Forma de liberação & Conta corrente do empreendedor & Conta corrente da empresa \\
\hline TAC & $1 \%$ & $1 \%$ \\
\hline IOF & 0 & 0 \\
\hline Garantia & Real ou Fidejussória & Real ou Fidejussória \\
\hline
\end{tabular}

Fonte: Elaborado pelos autores.

\section{ANÁLISE DE RISCO DAS OPERAÇÕES DE MICROCRÉDITO DOS BANCOS, MEDIANTE AS TÉCNICAS DE DURAÇÃO E CONVEXIDADE}

Foram realizadas simulações de operações de microcrédito por meio do Sistema de Amortização Constante (SAC), considerando as variáveis prazos, taxas, prestações e carência, estipulados por cada instituição. Foi utilizado o software Excel através do qual foram calculados os valores das operações, o saldo devedor e o valor mensal presente.

Conforme demonstrado em Fabozzi (2000), para cada linha de crédito foi determinado um aumento do retorno do bônus por um número pequeno de pontos-base, de forma a encontrar o novo preço em nível mais elevado e, ao mesmo tempo foi determinada a redução do retorno do bônus pelo mesmo número de pontos-base, para então recalcular o novo preço. Seguem-se os resultados apurados. 


\section{O caso do Banco do Nordeste do Brasil}

O Banco do Nordeste do Brasil, através do Crediamigo trabalha com trinta e seis opções de linhas de microcrédito para pessoa física, com taxa de juros de 0,64\% e sem carência. Aplicadas as técnicas de duração e convexidade como medida de sensibilidade do papel às flutuações das taxas de juros, tem-se que o aumento da maturidade nas operações provoca uma elevação da duração.

O Gráfico 1 representa a volatilidade do ativo e o risco da operação conforme aumenta a Duração. Para uma determinada duração, uma obrigação ou uma carteira de obrigações será tanto mais convexa quanto maior for a dispersão dos seus fluxos de caixa, conforme Fabozzi (2000). Este resultado pode ser confirmado pelo cálculo da convexidade representado no Gráfico 2.

Gráfico 1 - Banco do Nordeste: duração da operação em função da parcela - 2012

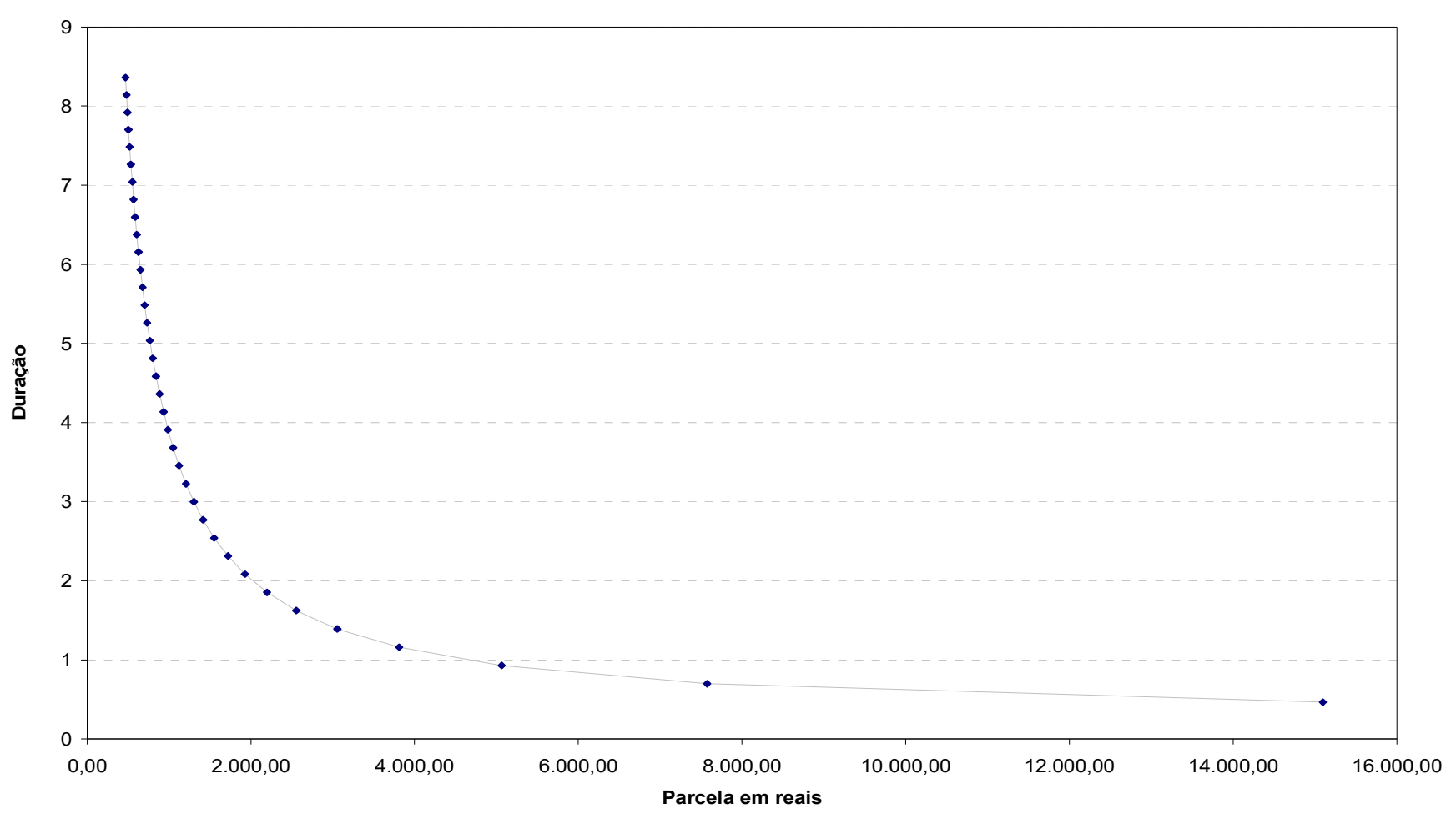

Fonte: Elaborado pelos autores 
Gráfico 2 - Banco do Nordeste: convexidade da operação em função da parcela - 2012

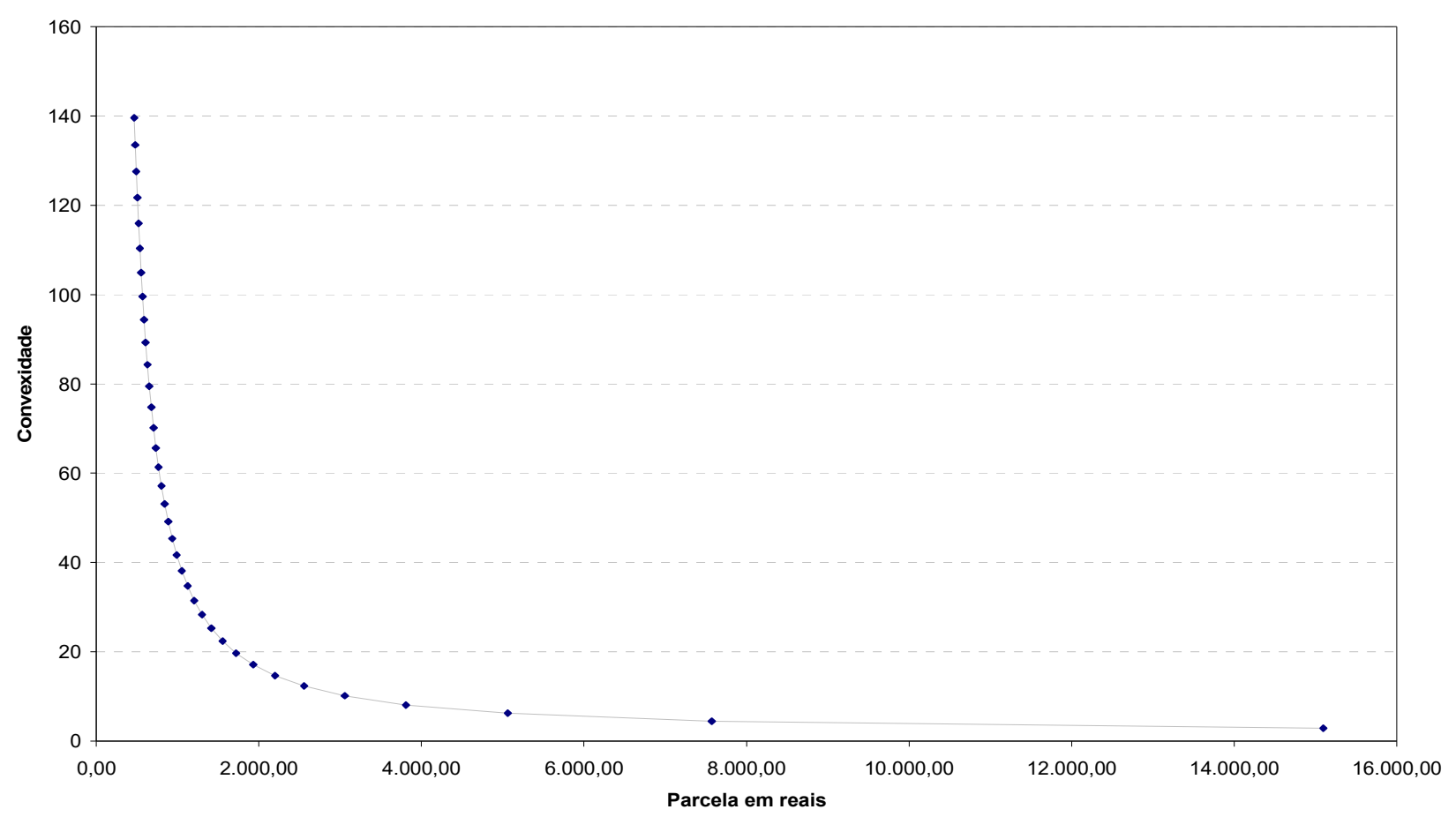

Fonte: Elaborado pelos autores

Nas opções de linha de crédito em que a taxa de juros é baixa e os prazos alongados, verifica-se que a convexidade é elevada, o que significa que, em situação de mudança no contexto econômico, essas operações representam elevado risco de perda para a instituição, podendo comprometer sua sustentabilidade. Os clientes com perfil de baixa renda, característica do público que a Programa Nacional de Microcrédito Produtivo Orientado busca atender, optam por prazos maiores de pagamento, por serem as parcelas de menor valor. Este é um fator qualitativo que corrobora a suposição de que essas linhas de crédito representam maior risco para a instituição microfinanceira.

Os valores da duração e convexidade mostram que as operações de microcrédito com taxas de juros mais baixas e maturidade mais elevada apresentam maior risco para a instituição. Apresenta-se, assim, um cenário onde o risco de inadimplência, no caso de uma prestação maior, confronta-se com o risco de perda de liquidez pelo banco, em função de um prazo maior. 


\section{O Caso Caixa Econômica Federal}

A Caixa Econômica Federal oferece doze opções de crédito, com a mesma taxa de juros de $(0,64 \%)$ e sem carência. Os resultados demonstram que, quanto menor for a maturidade de uma opção, menor será sua duração o que representa menor risco para a Instituição.

Os Gráficos 3 e 4, a seguir, demonstram que os resultados da taxa da convexidade acompanham a medida da duração. Estes resultados corroboram os estudos de Fabozzi (2000) e Assaf Neto (2007). Percebese assim, uma coerência entre aos resultados uma vez que a convexidade acompanhou a duração.

Gráfico 3 - Caixa Econômica Federal: duração da operação em função da parcela - 2012

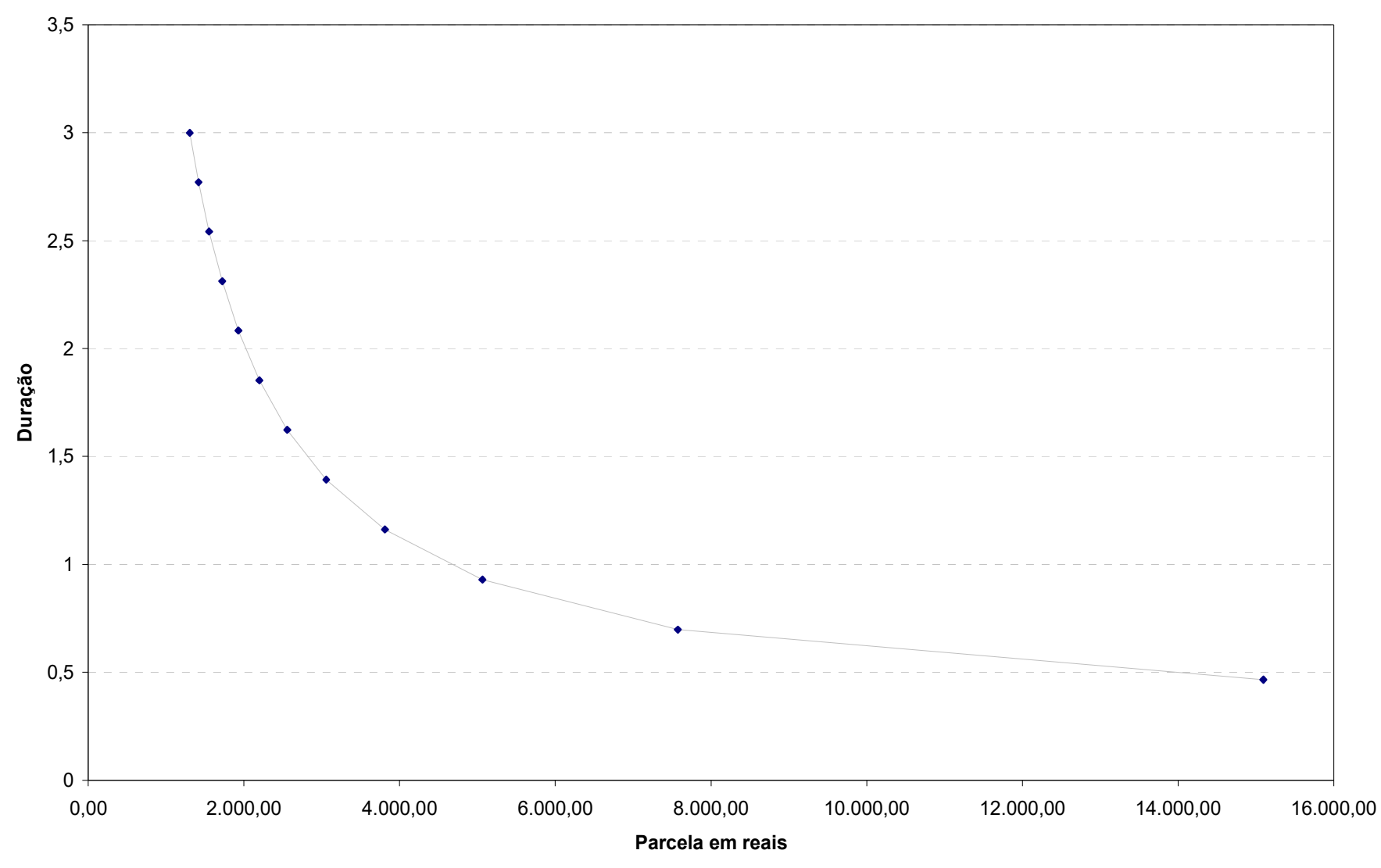

Fonte: Elaborado pelos autores 
Gráfico 4 - Caixa Econômica Federal: convexidade da operação em função da parcela - 2012

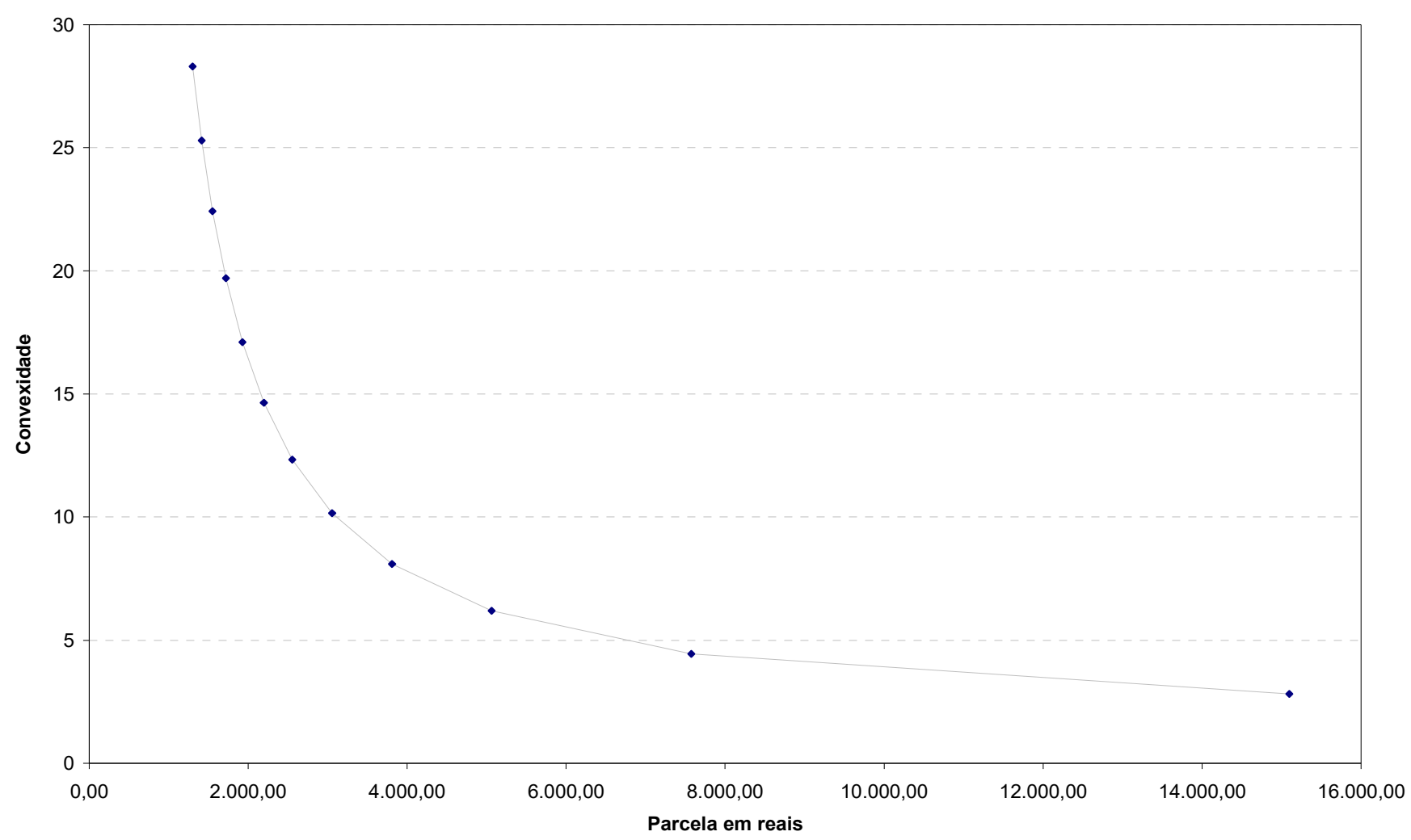

Fonte: Elaborado pelos autores

\section{O Caso Banco do Brasil}

O Banco do Brasil trabalha com uma carteira de trinta opções, com prazos que variam de 4 a 18 meses, com carência de 1 a 2 meses e taxa de juros de 0,64\%. Verificou-se a mesma tendência dos resultados obtidos nas instituições analisadas anteriormente, o que corrobora a pertinência da utilização das técnicas de duração e convexidade para medição da volatilidade dos preços de títulos e para a gestão de risco. Os resultados desta opção de carteira do BB coincidem com os apurados nas duas carteiras anteriores: Quanto maior é a duração modificada, maior a volatilidade de preço do bônus e maior, também, o risco da operação, conforme evidenciam os resultados confirmando os estudos de Fabozzi (2000).

O cálculo da duração, neste caso, apresentou a dispersão dos fluxos de caixa com as carências dadas de trinta e sessenta dias. Os resultados demonstram que os prazos de retorno do investimento variam de 1 a 5 meses, dependendo da maturidade do bônus e das carências, conforme mostra o Gráfico 5 .

O cálculo da convexidade desta carteira revela o fenômeno já verificado quanto a tendência de acompanhamento dos resultados do cálculo da duração, ou seja, quanto maior for a duração, maior também será a convexidade verificada, sendo esta última uma medida mais sensível da volatilidade dos preços do bônus e do risco da operação (Gráfico 6).

Essas medidas de risco evidenciam que, em uma situação de instabilidade econômica, em que venha a ser verificada uma variação significativa da taxa referencial, tais operações representam elevado risco de 
perda para as instituições, conforme apontam os estudos de Assaf Neto (2007), Fabozzi (2000), Piazzesi e Schneider (2010), Hatchondo e Martinez (2009).

Gráfico 5 - Banco do Brasil: duração da operação em função da parcela - 2012

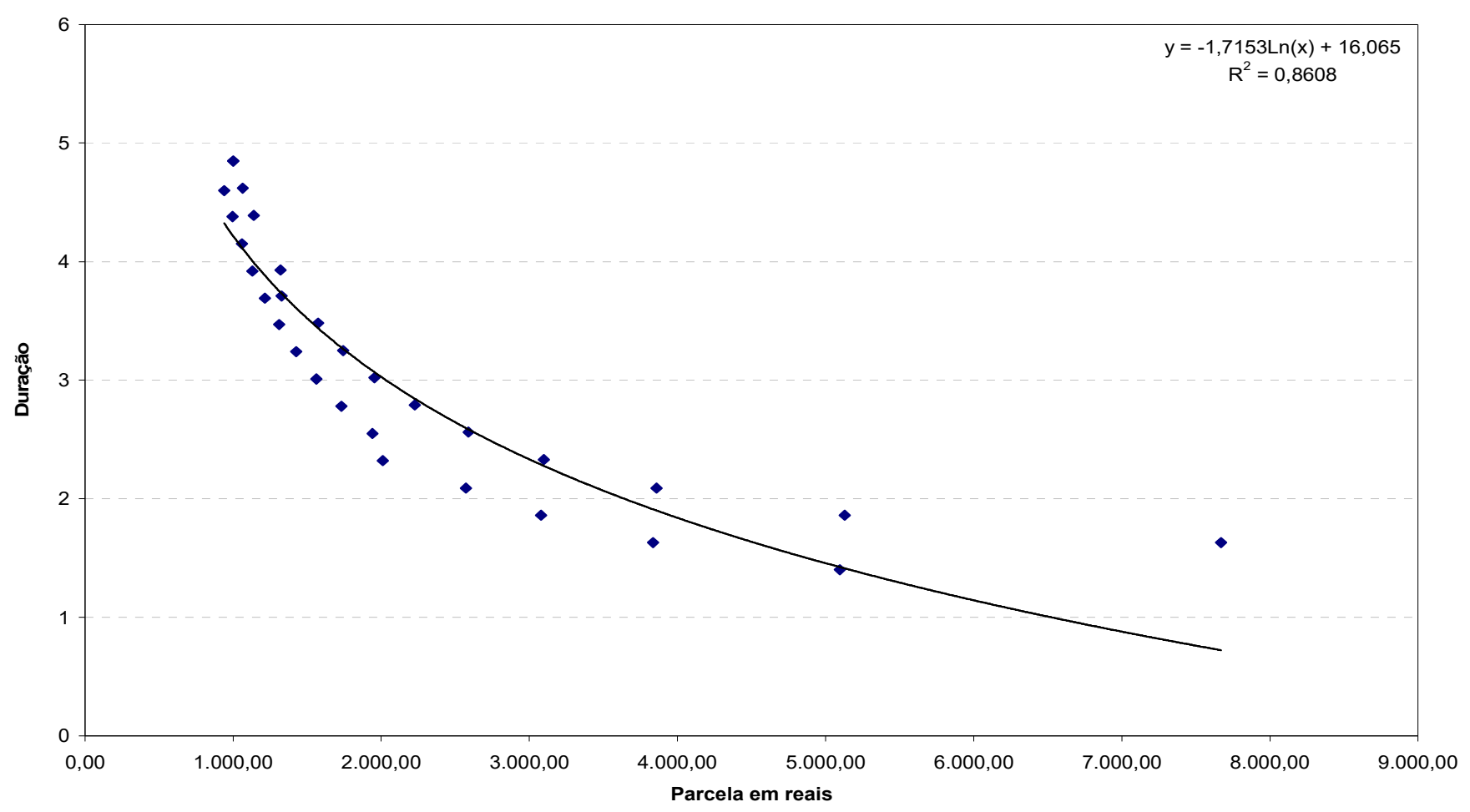

Fonte: Elaborado pelos autores

Gráfico 6 - Banco do Brasil: convexidade da operação da parcela - 2012

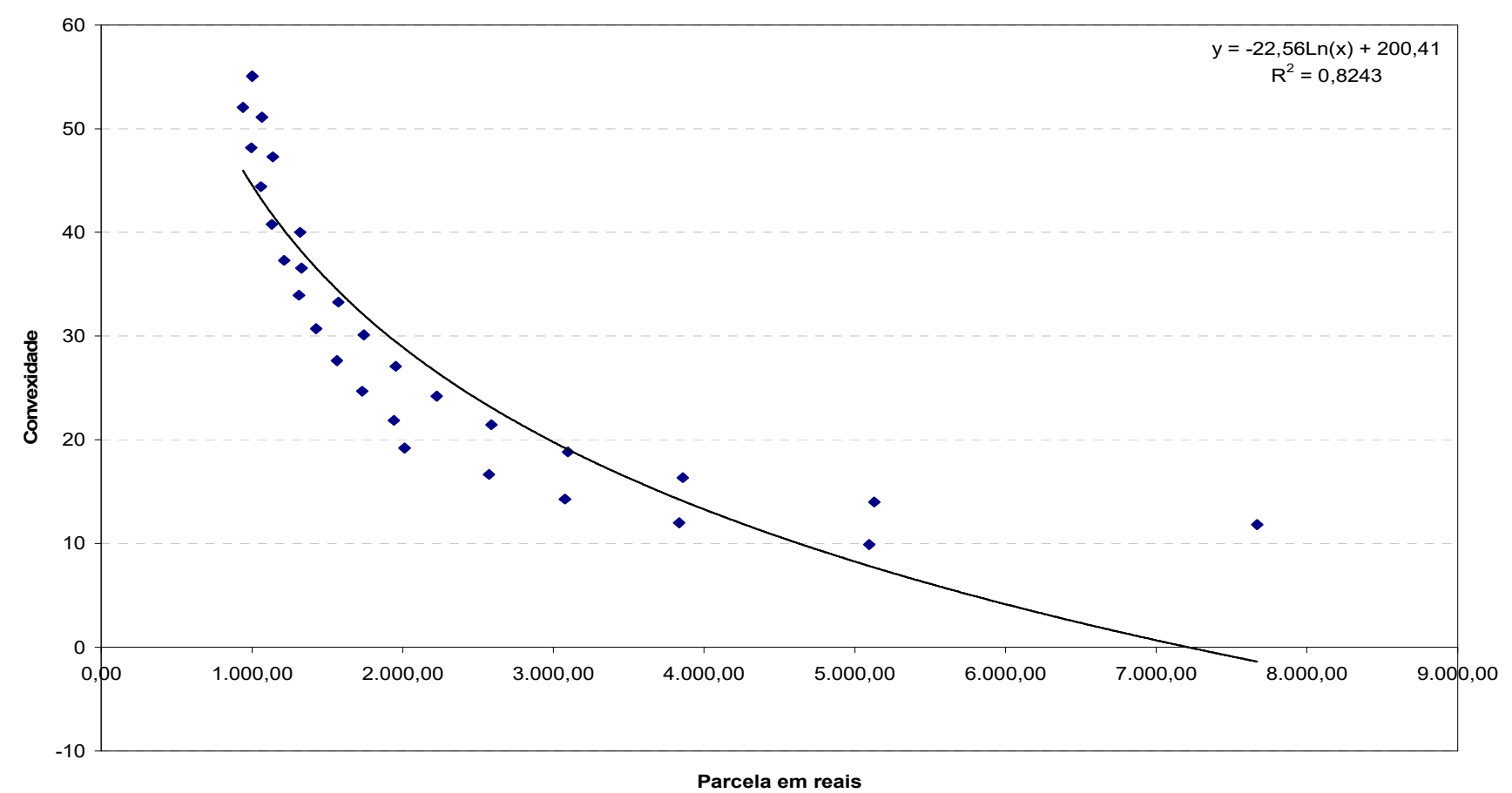

Fonte: Elaborado pelos autores 
As instituições financeiras pesquisadas atuam como extensões do Programa CRESCER, do Governo Federal, que prevê a implantação do microcrédito como estratégia de combate à pobreza no Brasil: o Banco do Nordeste, através do Crediamigo, detém mais de $60 \%$ do mercado de microcrédito brasileiro, concentrado nos estados nordestinos, Espírito Santo e norte de Minas Gerais. Enquanto o Programa Crescer, do Governo Federal, tem apenas um ano de implantação, o Crediamigo já conta com longa experiência, apresentando resultados positivos da implantação deste programa desde 2002.

O Crediamigo segue o modelo de microcrédito adotado por Yunus (2000), quanto às garantias do aval solidário, diferentemente das outras instituições que adotam o modelo tradicional do mercado financeiro, quais sejam, as garantias reais e fidejussórias, estas últimas também chamadas de garantias pessoais, expressando a obrigação que alguém assume, ao garantir o cumprimento de obrigação alheia, caso o devedor não o faça.

As três instituições pesquisadas trabalham em consonância com as características de operação de crédito estipuladas pelo Programa CRESCER quais sejam: juros de 0,64\% ao mês, limites que variam de $R \$ 150,00$ a $R \$ 15.000,00$ e prazos de até 36 meses. A taxa anual de $8 \%$ está acima da taxa Selic $(7,96 \%)$ com uma margem de lucro superior a $9,74 \%$.

Este estudo verificou, por meio da análise quantitativa, que as oscilações nas taxas constituem um risco, que pode causar problemas nos resultados financeiros das Instituições de Microfinanças se os retornos obtidos no cumprimento das obrigações forem insuficientes.

Em síntese, os resultados da pesquisa confirmaram as propriedades da duração e da convexidade. Foi possível levantar que:

a) quanto maior for a duração modificada, maior será a volatilidade do preço do bônus e maior também o risco da operação;

b) uma obrigação ou uma carteira de obrigações com determinada duração será tanto mais convexa quanto maior for a dispersão dos seus fluxos de caixa;

c) as medidas de duração e convexidade revelam que as operações de microcrédito com taxas de juros mais baixas e maturidade mais elevadas apresentam maior risco para a instituição;

d) que quanto menor for a maturidade de uma opção, menor será sua duração o que representa menor risco para a instituição;

e) como a medida da convexidade acompanhou a medida da duração em cada carteira, constatou-se a existência de correlação entre os resultados;

f) nas três carteiras estudadas, verificou-se a mesma tendência nos resultados, o que corrobora a pertinência da utilização das técnicas para medição da volatilidade de preços e para a gestão de risco. 
$\mathrm{Na}$ análise qualitativa dos dados pode-se levantar os seguintes resultados:

a) O público do Microcrédito Produtivo Orientado tem preferência por contratar empréstimos com prazos maiores o que aumenta o risco dessas operações;

b) Observou-se também que o atendimento prestado pelos agentes de crédito pode estar aquém do pretendido, por falta de recursos humanos preparados para atender à demanda dos clientes;

c) Os tomadores de empréstimo demonstram falta de conhecimentos e experiências na administração do negócio;

d) Evidenciou-se dificuldades para a liberação de crédito, em razão de restrições ao cadastro do cliente;

e) Os agentes relataram elevada incidência de casos em que o valor do crédito autorizado não preenche a expectativa do cliente;

f) A falta de funcionamento das redes de colaboração para o alcance dos objetivos do microcrédito pode comprometer os resultados esperados do Programa Nacional de Microcrédito Produtivo Orientado.

\section{CONCLUSÃO}

Os resultados obtidos na análise quantitativa comprovaram a exposição das instituições pesquisadas a riscos, nas operações de microcrédito realizadas, como constatado pela aplicação das técnicas de duração e convexidade. Foram confirmadas as seguintes tendências esperadas: que quanto maior for a duração modificada, maior será a volatilidade do preço do bônus; uma obrigação ou uma carteira de obrigações com determinada duração será tanto mais convexa quanto maior for a dispersão dos seus fluxos de caixa; as medidas de duração e convexidade mostram que as operações de microcrédito com taxas de juros mais baixas e maturidade mais elevada apresentam maior risco; quanto menor a maturidade de uma opção, menor será sua duração, o que representa menor risco para a instituição.

Os resultados apurados na análise qualitativa realizada apontaram riscos nas operações de microcrédito, decorrentes de entraves burocráticos para a concessão dos valores solicitados; insuficiência de recursos humanos capacitados para prestar, nas instituições de microfinanças, assessoria financeira a cada tomador de empréstimo; despreparo do empreendedor quanto à gestão global do próprio negócio; carência de operacionalidade da rede de colaboração sugerida pelo Programa Crescer, iniciativa do Governo Federal para dar suporte à gestão de negócios, mediante o acesso ao crédito orientado.

Evidenciou-se que nos últimos anos, foram grandes os avanços na política de transferência de renda, no acesso a bens e serviços para a população da base da pirâmide no Brasil; no entanto, ainda há muito a ser feito para aumentar a abrangência do acesso a esses benefícios em prol das conquistas de liberdades individuais. É imprescindível haver conexão entre os diversos atores, para que o desenvolvimento econômico e transformação social da população sejam alcançados.

As análises quantitativa e qualitativa desenvolvidas nesta pesquisa apontam para o risco das operações de microcrédito. Em face da relevância da matéria, recomenda-se o desenvolvimento de outros estudos, que analisem a gestão de risco por meio de técnicas mitigadoras de risco, que podem ser implementadas por meio de mudanças na regulamentação, na gestão, na melhoria das parcerias e nas garantias exigidas. 


\section{REFERÊNCIAS}

AIZENMAN. Joshua; HUTCHISON. Michael; JINJARAK. Yothin. What is the risk of European sovereign debt defaults? Fiscal space, CDS spreads and market pricing of risk. Journal of International Money and Finance, v. 34, p. 37-59. 2013. ASSAF. NETO, Alexandre Finanças corporativas e valor. São Paulo: Atlas, 2007.

Banco do Nordeste do Brasil -BNB. Crediamigo. Disponível em: <http://www.bnb.gov.br/content/aplicacao/Produtos_e_Servicos/Crediamigogerados/c>. Acesso em: 15 out. $2012 \mathrm{c}$. BARDIN, Laurence. Análise de conteúdo. Tradução. Luís Antero Reto e Augusto Pinheiro. Lisboa: Edições 70, 2002.

BARONE; Marcelo; ZOUAIN, Deborah Moraes. Excertos sobre política pública de acesso ao crédito como ferramenta de combate à pobreza e inclusão social: o microcrédito na era FHC. Revista de Administração Pública - RAP, Rio de Janeiro: FGV/EBAPE, 2007. Disponível em: <http://www.scielo.br/pdf/rap/v41n2/10.pdf>. Acesso em: 11 set. 2010.

BAI, Y.; ZHANG, J. Duration of sovereign debt renegotiation. Journal of International Economics. v.86.p252-268. 2012.

BRASIL. Decreto $n^{\circ} 6.607$, de 21 de outubro de 2008. Altera o valor da renda bruta anual do Programa Nacional de Microcrédito Produtivo Orientado. Diário Oficial da União, Brasília, 22 de outubro de 2008. Disponível em: <http://www.planalto.gov.br/ccivil_03/_Ato2007-2010/2008/Decreto/D6607.htm> Acesso em: 24. mar. 2010.

BRASIL. Decreto $n^{\circ} 7.492$, de 2 de junho de 2011. Institui o plano Brasil Sem Miséria. Diário Oficial da União, Brasília, 3 de junho de 2011. Disponível em:

< http://www.planalto.gov.br/ccivil_03/_Ato2011-2014/2011/Decreto/D.7492.htm>. Acesso em: 24 out. 2011.

BRASIL. Ministério do Desenvolvimento Social. Caderno Brasil Sem Misérias. Disponível:

<www.cve.saude.sp.gov.br/htm/hans/pdf/caderno_brasil_sem_miseria.pdf>. Acesso em: 10 abr. 2012b.

Caixa Econômica Federal. Disponível em: <http://www.caixa.gov.br/voce/Credito/mpo_crescer/index.asp>. Acesso em: 15 out. 2012.

DUARTE JR., A. M. A importância do gerenciamento de riscos corporativos em bancos. In: DUARTE JR., A. M.; VARGA, G. (Orgs.). Gestão de riscos no Brasil. Rio de Janeiro: Financial Consultoria, 2003.

FABOZZI, Frank J. Mercados, Análise e Estratégia de Bônus: Títulos de Renda Fixa. Rio de Janeiro: Qualitymark, 2000. $793 p$.

FERREIRA, A. B. de H. Dicionário Aurélio Básico da Língua Portuguesa. Rio de Janeiro: Nova Fronteira, 1995.

GREENWOOD, R.; HANSON, S.; STEIN, J.C. A Gap-Filling Theory of Corporate Debt

Maturity Choice. The Journal of Finance. v. LXV, no. 3, p.993-1028. 2010.

HATCHONDO. Juan Carlos; MARTINEZ. Leonardo. Long-duration bonds and sovereign defaults. Journal of International Economics, v.79, p.117-125. 2009.

JUNQUEIRA, Rodrigo Gravina Prates; ABRAMOVAY, Ricardo. A Sustentabilidade das microfinanças solidárias. Revista de Administração, São Paulo, v.40, n.1, p.19-33, jan./fev./mar. 2005.

MENDES, Maria Silvânia Valente. Microcrédito e qualidade de vida urbana: o caso dos tomadores do empréstimo no Banpará S/A - Região Metropolitana de Belém 2009. 141f. Dissertação (Mestrado em desenvolvimento e Meio Ambiente Urbano) - Universidade da Amazônia, Belém.

PASSOS, Alessandro Ferreira. et al. Focalização, sustentabilidade e marco legal: uma revisão da literatura de microfinanças. Disponível em: <www.mte.gov.br/pnmpo/focalizacao_sustentabilidade_marco_legal.pdf>. Acesso em: 13 mai. 2012.

PIAZZESI, Monika; SCHNEIDER, Martin. Association Interest Rate Risk in Credit Markets. The American Economic Review, v. 100, No. 2, Papers and Proceedings Of Theo One Hundred Twenty Second Annual Meeting Of The American Economic Association, pp. 579-584. 2010. Published by: American Economic Disponível em: http://www.jstor.org/stable/27805062 .Acesso em: 08/04/2013.

PRAHALAD, C. K. A riqueza na base da pirâmide: Como erradicar a pobreza com lucro. Porto Alegre: Bookman, 2010. PROGRAMA DAS NAÇÕES UNIDAS PARA O DESENVOLVIMENTO DO BRASIL - PNUD BRASIL. Erradicar a extrema pobreza e a fome: nosso trabalho pelo objetivo. Disponível em: <http://www.pnud.org.br/odm1.aspx>. Acesso em: 25 fev. 2012 c.

SILVA, José Pereira da. Gestão e análise de risco de crédito / 5. Ed. São Paulo: Atlas, 2006.

SOARES, Marden Marques;SOBRINHO, Abelardo Duarte de Melo. Microfinanças : o papel do Banco Central do Brasil e a importância do cooperativismo de crédito.Brasília : BCB, 2008. 
VARGAS, Daniela Bicalho. Monografia: Operações de Financiamento Habitacional: análise de risco de crédito por meio da aplicação das técnicas duração e convexidade. Faculdade de Ciências Econômicas de Minas Gerais. Universidade Federal de Minas Gerais. 2012

VENTURA, Eloy Câmara. A evolução do crédito da Antiguidade aos dias atuais. Curitiba: Juruá, 2000

YUNUS, Muhammad. O banqueiro dos pobres. 4.ed. São Paulo: Editora Ática, 2001.

WORLD BANK CONSULTATIVE GROUP TO ASSIST THE POOREST - CGAP. Sostenibilidad financiera, focalización en los más pobres y efectos en el ingreso: ¿qué alternativas tienen las instituciones de microfinanciamiento?. 2007.

Disponível em: <www.worldbank.org>. Acesso em: 11 jun. 2012. 